10-19-2011

\title{
Immunization with the recombinant antigen Ss-IR induces protective immunity to infection with Strongyloides stercoralis in
} mice.

\author{
David Abraham \\ Thomas Jefferson University \\ Jessica A. Hess \\ Thomas Jefferson University \\ Rojelio Mejia \\ National Institutes of Health \\ Thomas.J. Nolan \\ University of Pennsylonal works at: https://jdc.jefferson.edu/mifp \\ Part of the Medicine and Health Sciences Commons

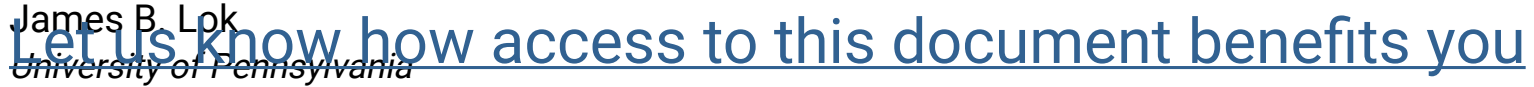

Recommended Citation

See next page for additional authors

Abraham, David; Hess, Jessica A.; Mejia, Rojelio; Nolan, Thomas J.; Lok, James B.; Lustigman,

Sara; and Nutman, Thomas B., "Immunization with the recombinant antigen Ss-IR induces

protective immunity to infection with Strongyloides stercoralis in mice." (2011). Department of

Microbiology and Immunology Faculty Papers. Paper 150.

https://jdc.jefferson.edu/mifp/150

This Article is brought to you for free and open access by the Jefferson Digital Commons. The Jefferson Digital Commons is a service of Thomas Jefferson University's Center for Teaching and Learning (CTL). The Commons is a showcase for Jefferson books and journals, peer-reviewed scholarly publications, unique historical collections from the University archives, and teaching tools. The Jefferson Digital Commons allows researchers and interested readers anywhere in the world to learn about and keep up to date with Jefferson scholarship. This article has been accepted for inclusion in Department of Microbiology and Immunology Faculty Papers by an authorized administrator of the Jefferson Digital Commons. For more information, please contact:

JeffersonDigitalCommons@jefferson.edu. 


\section{Authors}

David Abraham, Jessica A. Hess, Rojelio Mejia, Thomas J. Nolan, James B. Lok, Sara Lustigman, and Thomas B. Nutman 


\title{
Immunization with the recombinant antigen Ss-IR induces protective immunity to infection with Strongyloides stercoralis in mice
}

\author{
David Abraham ${ }^{a,}{ }^{,}$, Jessica A. Hess ${ }^{a}$, Rojelio Mejia ${ }^{b}$, Thomas J. Nolan ${ }^{c}$, James B. Lok ${ }^{c}$, Sara \\ Lustigman $^{d}$, and Thomas B. Nutman ${ }^{b}$ \\ aDepartment of Microbiology and Immunology, Thomas Jefferson University Philadelphia, PA \\ 19104 \\ bLaboratory of Parasitic Diseases, National Institutes of Allergy and Infectious Diseases, National \\ Institutes of Health, Bethesda, MD 20892 \\ 'Department of Pathobiology, University of Pennsylvania, School of Veterinary Medicine, \\ Philadelphia, PA 19104 \\ dThe Lindsley F. Kimball Research Institute, New York Blood Center, New York, NY 10021
}

\begin{abstract}
Human intestinal infections with the nematode Strongyloides stercoralis remain a significant problem worldwide and a vaccine would be a useful addition to the tools available to prevent and control this infection. The goal of this study was to test single antigens for their efficacy in a vaccine against $S$. stercoralis larvae in mice. Alum was used as the adjuvant in these studies and antigens selected for analysis were either recognized by protective human IgG (Ss-TMY-1, SsEAT-6, and Ss-LEC-5) or were known to be highly immunogenic in humans (Ss-NIE-1 and SsIR). Only mice immunized with the Ss-IR antigen demonstrated a significant decrease of approximately $80 \%$ in the survival of larval parasites in the challenge infection. Antibodies, recovered from mice with protective immunity to $S$. stercoralis after immunization with Ss-IR, were used to locate the antigen in the larvae. Confocal microscopy revealed that IgG from mice immunized with Ss-IR bound to the surface of the parasites and observations by electron microscopy indicated that IgG bound to granules in the glandular esophagus. Serum collected from mice immunized with Ss-IR passively transferred immunity to naïve mice. These studies demonstrate that Ss-IR, in combination with alum, induces high levels of protective immunity through an antibody dependent mechanism and may therefore be suitable for further development as a vaccine against human strongyloidiasis.
\end{abstract}

\section{Keywords}

Strongyloides stercoralis; Ss-IR; recombinant vaccine

\section{(C) 2011 Elsevier Ltd. All rights reserved.}

*Corresponding author: David Abraham, Ph.D., Department of Microbiology and Immunology, Thomas Jefferson University, 233 South $10^{\text {th }}$ Street, Philadelphia, PA 19107, Telephone: 215-503-8917, Fax: 215-923-9248, David.Abraham@ Jefferson.edu.

Publisher's Disclaimer: This is a PDF file of an unedited manuscript that has been accepted for publication. As a service to our customers we are providing this early version of the manuscript. The manuscript will undergo copyediting, typesetting, and review of the resulting proof before it is published in its final citable form. Please note that during the production process errors may be discovered which could affect the content, and all legal disclaimers that apply to the journal pertain. 


\section{Introduction}

Human infection with Strongyloides stercoralis remains a significant health problem in both resource-rich and resource-poor nations [1] and is estimated to infect 30-100 million people. It is a nematode infecting humans, primates and dogs that causes a range of relatively benign symptoms during acute infection. Chronic infections may persist for the lifetime of the host and are commonly subclinical. However, chronically infected individuals who become immunosuppressed often because of corticosteroid treatment or infection with HTLV-1 can develop hyperinfection syndrome, a condition that can be life threatening [2-4]. Although chemotherapy (albendazole or ivermectin) is available for S. stercoralis infections, efficacy is rarely $100 \%$ [5-6] and the potential for drug resistance is real [7]. Recent findings in humans infected with Onchocerca volvulus confirm the potential for worms to develop resistance to ivermectin [8]. Moreover, treatment of the potentially lethal hyperinfection syndrome remains problematic. Thus, given the potential for fatal disease associated with $S$. stercoralis infection, the difficulty in treatment of hyperinfection, and the potential for resistance to the drugs used to treat $S$. stercoralis, there remains a need for prophylactic vaccines against this infection.

Many approaches have been tested in attempts to produce experimental vaccines against nematode infections using a plethora of antigen sources, formulations and immunization protocols, with levels of reduction in worm burden induced by these vaccines ranging from 30-90\% [9-10]. Among the intestinal helminths, experimental vaccines against hookworm infections have been developed using single antigens derived from larvae [11-15] or adult worms [16] and administered with various adjuvants including alum $[12-13,16]$. There was a reduction of approximately $30 \%$ in challenge hookworm survival in animals immunized with these vaccines $[11,14-16]$. This relatively low level of protection, however, was sufficient to move one of these vaccines toward clinical development and human testing [12].

The immune response to $S$. stercoralis, though poorly characterized is required for the control of infection and the prevention of hyperinfection [17]. Immunization of mice with $S$. stercoralis live larvae resulted in high levels of protective immunity that was shown to be antibody dependent [18-21]. In addition, immunization of mice with alum-adjuvanted soluble proteins derived from $S$. stercoralis larvae also generated antibody-dependent protective immunity. Antibodies from these protected mice were used to affinity purify and isolate protective $S$. stercoralis antigens; these antigens, when pooled, induced a significant protective immunity, with $83 \%$ of the challenge larvae killed [22].

Antibodies from humans chronically-infected with S. stercoralis were also effective at killing S. stercoralis larvae. Immunization of mice with antigens recognized by "protective" human IgG with alum induced a 76\% reduction in larval survival [20]. This same human IgG pool was used to identify specific vaccine candidates, three of which (SsTMY-1, SsEAT-6, and Ss-LEC-5) could be characterized at a molecular level. When used in DNAbased immunization protocols, only Ss-eat-6 induced a 35\% reduction in larval survival. Serum from mice immunized with the DNA encoding Ss-eat-6 was also capable of transferring this partial immunity [23].

The goal of this study was to test single protein antigens for their efficacy in a vaccine against $S$. stercoralis larvae in mice. Alum was selected as the adjuvant to be used in these studies based on past performance in vaccines against $S$. stercoralis $[20,22]$ and because it preferentially induces Th2 responses [24-25], which are critical in the protective immune response induced by live $S$. stercoralis larvae [26]. Antigens selected for this study were either recognized by protective human IgG (Ss-TMY-1 Ss-EAT-6, and Ss-LEC-5 [23]) or 
were known to be highly immunogenic in humans and Strongyloides-specific (Ss-NIE-1 and Ss-IR [27]). Of the five antigens tested, only Ss-IR was able to consistently induce a high level of antibody dependent protection.

\section{Materials and Methods}

\subsection{Production of the antigens}

The DNA of each of the potential antigens - Ss-tmy-1(BE579623), Ss-eat-6 (BE581796), Ss-lec-5 (BG227948), Ss-nie-1 (AF136445.1), and Ss-ir (EU285565.1) - was subcloned by PCR from plasmids containing the entire coding sequence (synthesized by Genscript [Piscataway, NJ] with codon usage optimized for expression in baculovirus) into Gateway Entry ${ }^{\mathrm{TM}}$ plasmids using sequence specific oligonucleotides. Each of these 5 separate Gateway Entry plasmids were used to make three Gateway Destination ${ }^{\mathrm{TM}}$ vectors for expression in Escherichia coli, baculovirus, and Kluyveromyces lactis respectively. For any given antigen, only a single expression system was used for antigen production based on the system that gave the highest expression level and ease of purification in preliminary testing. The expression of the purified proteins can be viewed in Figure 1.

Each protein was cloned by PCR from plasmid DNA [28] using primers corresponding to the $5^{\prime}$ and $3^{\prime}$ ends of the mature Ss-IR, Ss-EAT-6, Ss-LEC-5, Ss-NIE, Ss-TMY-1 gene and an adapter-overlap to introduce Gateway recombination sites and an insect cell GP67 signal peptide leader sequence into the gene. PCR was carried out using Phusion ${ }^{\mathrm{TM}}$ polymerase (New England Biolabs) under standard conditions using a 20 second extension time. The final PCR product contained the mature gene with a GP67 leader sequence at the 5' end preceded by a Gateway attB1 site, and a His6 tag at the carboxyterminal end followed by a Gateway attB2 site. The PCR products were cleaned using the QiaQuick ${ }^{\mathrm{TM}}$ PCR purification kit (Qiagen), and recombined into pDonr253 using the Gateway BP recombination reaction (Invitrogen) with the manufacturer's protocols.

2.1.1 Subcloning of Ss-IR-His6-The sequence-verified Entry clone was subcloned by Gateway LR recombination (Invitrogen) expression vectors. The expression clones were then transformed into E. coli DH10Bac (Invitrogen), and plated on selective media containing gentamicin, kanamycin, tetracycline, IPTG, and X-gal as per the manufacturer's protocols. White colonies were selected from these plates, and DNA was generated by alkaline lysis plasmid preparation, and verified by PCR amplification.

2.1.2 Expression of GP67 -His6 constructs in High Five (H5) insect cells-The bacmid DNA was transfected into Sf-9 cells to create a recombinant baculovirus stock. The bacmid DNA was combined with Insect Gene Juice (Novagen) transfection reagent and then mixed with $100 \mathrm{ml}$ of Sf-9 cells at $1.5 \times 10^{6} / \mathrm{ml}$ in HyClone Insect-SFX medium (HyClon, Logan, UT). Large-scale expression was performed in Corning three liter Erlenmeyer flasks (Corning, NY). The cell density at infection was $1.53 \times 10^{6} / \mathrm{ml}$ and the culture was infected at a multiplicity of infection (MOI) of 3 . Following incubation on a shaker at $100 \mathrm{rpms}$ at $21^{\circ}$ $\mathrm{C}$ for 72 hours the supernatant was collected.

2.1.3 Purification of His6 containing proteins-Culture supernatant $(200 \mathrm{ml})$ from the insect/baculovirus or yeast expression was dialyzed twice (4 hr each) against 4 liters of $20 \mathrm{mM}$ HEPES, pH 7.3, $300 \mathrm{mM} \mathrm{NaCl}$. Sample was adjusted to $45 \mathrm{mM}$ imidazole and applied to a $1 \mathrm{ml}$ Histrap column (GE Healthcare, pre-equilibrated to the sample buffer conditions) using an AKTA Purifier FPLC (GE Healthcare). Sample was applied at $0.2 \mathrm{ml} /$ min, washed to baseline absorbance (A280) and proteins eluted with a linear gradient of imidazole from $45 \mathrm{mM}$ to $400 \mathrm{mM}$ over $20 \mathrm{ml}$. Elution was collected in $40 \times 0.5 \mathrm{ml}$ 
fractions and these were analyzed by SDS-PAGE with Coomassie staining. Positive fractions were pooled and the sample dialyzed (as above) to 1xPBS, pH 7.2. Sample (8 ml) was concentrated to $0.7 \mathrm{ml}$ using an Amicon Ultra (Millipore) 5K MWCO concentrator unit.

\subsection{Animals}

Male BALB/cByJ mice, six to eight weeks old, were obtained from Jackson Laboratory (Bar Harbor, ME). Animals were housed in filter-top microisolator boxes (Lab Products Inc., Maywood, NJ) in pathogen-free conditions, under light- and temperature-controlled conditions in the Thomas Jefferson University animal facility. All protocols utilizing animals were reviewed and approved by the Institutional Animal Care and Use Committee (IACUC) of Thomas Jefferson University.

\subsection{Challenge infections in diffusion chambers}

Strongyloides stercoralis larvae were cultured from the fresh stools of infected laboratory dogs. Larvae were harvested from charcoal cultures and washed via centrifugation and resuspension in sterile 1:1 NCTC-135 and IMDM medium supplemented with $100 \mathrm{U} / \mathrm{ml}$ penicillin, $0.1 \mathrm{mg} / \mathrm{ml}$ streptomycin (Cellgro, Manassas, VA), $0.1 \mathrm{mg} / \mathrm{ml}$ gentamicin (Invitrogen, Carlsbad, CA) and $0.25 \mathrm{mg} / \mathrm{ml}$ levaquin (Ortho-McNeil, Raritan, NJ). Diffusion chambers were constructed from $14 \mathrm{~mm}$ Lucite rings covered with $2.0 \mu \mathrm{m}$ pore-size polycarbonate membranes (Millipore, Bedford, MA) using cyanoacrylate adhesive (Superglue Corp., Hollis, NY) and fused together with an adhesive consisting of 1:1 1,2dichloroethane (Fisher Scientific, Pittsburgh, PA) and acryloid resin (Rohm and Haas, Philadelphia, PA) and then sterilized via 100\% ethylene oxide followed by 12 hours of aeration.

\subsection{Immunization and challenge protocol}

Mice were immunized with $25 \mu \mathrm{g}$ of each recombinant antigen in $0.1 \mathrm{ml}$ of PBS with $0.1 \mathrm{ml}$ of 1:10 Rehydragel LV (alum) in PBS (General Chemical, Parsippany, NJ) for a $0.2 \mathrm{ml}$ injection. Mice were immunized with the solution subcutaneously in the nape of the neck on day 0 followed by a booster immunization 14 days later with the same quantity of antigen with alum. On day 28 mice were challenged with a diffusion chamber containing 50 larvae implanted in a subcutaneous pocket on the rear flank of the mouse. Four days after implantation, the diffusion chambers were recovered and larval survival was determined based on morphology and mobility of the worms. Serum was collected for subsequent antibody analysis. Host cells within the diffusion chamber were analyzed by centrifugation onto slides using a Cytospin 3 (Shandon Inc., Pittsburgh, PA) and then stained for differential counts with DiffQuik (Baxter Healthcare Corp., Miami, Florida.

\subsection{ELISA}

Serum levels of antigen-specific IgG antibodies were measured by ELISA. Maxisorp 96 well plates (Nunc Nalgene International, Rochester, NY) were coated with a $2 \mu \mathrm{g} / \mathrm{ml}$ solution of recombinant antigen in $50 \mathrm{mM}$ Tris- $\mathrm{Cl} \mathrm{pH} 8.8$ overnight at $4^{\circ} \mathrm{C}$. Plates were blocked with borate buffer solution ( $0.17 \mathrm{M}$ Boric Acid, $0.12 \mathrm{M} \mathrm{NaCl}, 1 \mathrm{mM}$ EDTA, $0.25 \%$ BSA, $0.05 \%$ Tween 20, pH 8.5) (BBS) for 1 hour room temperature. Individual sera were diluted in BBS and incubated at $4^{\circ} \mathrm{C}$ overnight. Biotinylated anti-mouse $\operatorname{IgG}$ (Vector Laboratories Inc., Burlingame, CA) were diluted 1:250 for 1 hour room temp, followed by Extravidin peroxidase diluted 1:1000 (Sigma, St. Louis, MO) for 30 minutes. The peroxidase substrate ABTS (one component, KPL, Gaithersburg, MD) was added and optical densities were read at $410 \mathrm{~nm}$ in a Bio-Rad iMark Microplate reader (Bio-Rad, Hercules, CA). 


\subsection{Electron microscopy}

Larvae were fixed for $30 \mathrm{~min}$ in $0.25 \%$ glutaraldehyde in $0.1 \mathrm{M}$ phosphate buffer, $\mathrm{pH} 7.4$, containing $1 \%$ sucrose, and were then processed for immuno-electron microscopy. Thin sections of embedded larvae were incubated with purified IgG from naïve and immunized mice, followed by incubation with a suspension of $15 \mathrm{~nm}$ gold particles coated with protein A, as previously described [28].

\subsection{Confocal microscopy}

Larvae of S. stercoralis were fixed overnight in $4 \%$ paraformaldehyde at $4{ }^{\circ} \mathrm{C}$ and then prepared for immunofluorescence confocal microscopy. Whole larvae were washed three times with PBS and incubated in goat serum blocking buffer (10\% goat serum, $0.5 \%$ Triton $\mathrm{X}-100,0.1 \%$ sodium azide, $\mathrm{PBS}$ ) (GSBB) overnight at $4{ }^{\circ} \mathrm{C}$. GSBB was removed, and mouse sera (from immune or non-immune animals), at 1:25 dilution in GSBB, was added and incubated overnight at $4^{\circ} \mathrm{C}$ with gentle agitation (500 RPM) (Eppendorf, Thermomixer ${ }^{\circledR}$ ). The samples were then washed three times for 30 minutes each with bovine blocking buffer ( $1 \%$ bovine serum albumin, $0.5 \%$ Triton $\mathrm{X}-100,0.1 \%$ sodium azide, PBS) (BBB). Alexa Fluor 488-labelled goat anti-mouse IgG (Invitrogen) antibody was then added (1:1000 diluted in BBB) and incubated overnight at $4^{\circ} \mathrm{C}$ with gentle agitation (500 RPM). The following day $0.05 \mathrm{mg} / \mathrm{ml}$ of 4',6-diamidino-2-phenylindole (DAPI)(Pierce) was added to visualize the larvae nuclei and incubation continued for one hour. The larvae were then washed three times for 30 minutes each with PBS at $4^{\circ} \mathrm{C}$ with gentle agitation (500 RPM). After washing, the samples were mounted using Vectashield hard set mounting medium (Vector Laboratories Inc., Burlingame, CA) and examined using a LEICA SP5 X-WLL and analyzed using IMARIS ${ }^{\mathrm{TM}}$ software (v7.2, Bitplane Inc, St. Paul, MN). Additional controls were performed that included larvae with neither primary or secondary antibody and larvae with only labeled secondary antibody.

\subsection{Serum transfer}

Serum from naïve and immunized mice collected at the conclusion of the above experiments were pooled and filter sterilized with a $0.2 \mu \mathrm{m}$ pore size syringe filter and stored at $-80^{\circ} \mathrm{C}$. Passive transfer of the whole serum was done by mixing $100 \mu$ of serum with $100 \mu \mathrm{l}$ PBS and injecting it into the subcutaneous pocket surrounding the implanted diffusion chamber at the time of challenge. Recovery of diffusion chambers was at 24 hours post challenge for evaluation of larval survival and infiltrating cells.

\subsection{Statistical analyses}

The number of animals utilized for each of the test conditions is provided in the Figure legends. Data were analyzed by multifactorial analysis of variance ANOVA in Systat v.11 (Systat, Inc., Evanston, Illinois). Probability values less than 0.05 were considered significant.

\section{Results}

\subsection{Characteristics of the antigens}

Recombinant antigens Ss-IR, Ss-LEC-5, Ss-Eat-6, and Ss-NIE were prepared for the vaccination studies using a baculovirus expression system and Ss-TMY-1 was expressed in K. lactis. On SDS-PAGE Ss-IR had a MW of $\sim 31 \mathrm{kDa}$, Ss-LEC-5. had MW of $\sim 15,1823$ and $25 \mathrm{kDa}$, Ss-EAT-6 had a MW of $\sim 26 \mathrm{kDa}$, Ss-TMY-1 had MW of $\sim 8,11,35$ and $37 \mathrm{kDa}$ and Ss-NIE-1 had a MW of $\sim 30-34 \mathrm{kDa}$. 


\subsection{Immunization and challenge}

Mice were immunized with recombinant antigens in alum: (1) Ss-EAT-6, (2) SS-TMY-1, (3) Ss-LEC-5 (4) Ss-NIE and (5) Ss-IR. After two immunizations the mice received a challenge infection consisting of 50 larvae contained within a diffusion chamber. Only mice immunized with the Ss-IR antigen demonstrated a significant decrease, of approximately $80 \%$, in the survival of the parasites in the challenge infection (Figure 2A). The total number of cells and the differential analysis of the cells that migrated into the parasite microenvironment indicated that there were no differences in the number or types of cells based on immunization or exposure to alum for each of the antigens tested. Representative data are presented for the cells recruited into the diffusion chambers implanted in mice immunized with Ss-IR antigen (Figure 2B). IgG antibody responses were measured and all immunized mice developed IgG antibody response to the antigen with which they were immunized (Figure 2C). Based on these initial findings, two additional sets of vaccination/ challenge studies were performed. Vaccination with the same lot of Ss-IR used in the initial study and with a second lot of SsIR prepared $\sim 12$ months after the initial preparation gave the same degree of protection as seen initially (Figure 3).

\subsection{Location of Ss-IR in larvae}

Antibodies, recovered from mice with protective immunity to $S$. stercoralis after immunization with Ss-IR, were used to locate the antigen in the larvae. Confocal microscopy on intact worms revealed that IgG from mice immunized with Ss-IR bound to the surface of the parasites (Figure 4). By immuno-electron microscopy on fixed sectioned parasites, Ss-IR was localized to granules in the glandular esophagus (Figure 5). Taken together, these data suggest that the location of the Ss-IR protein makes it an attractive target for immune-mediated clearance and/or killing.

\subsection{Passive transfer of immunity}

Serum collected from the mice immunized with Ss-IR was subcutaneously transferred into naïve mice. The mice then received challenge infections in diffusion chambers implanted for 24 hours. Parasites were killed in mice that had passive transfer of serum from immunized mice (Figure 6A). Furthermore, cells found in the diffusion chambers did not differ between mice that received serum from immunized mice and serum derived from naïve mice. Neutrophils were the predominant cell type migrating into the parasite microenvironment (Figure 6B).

\section{Discussion}

The objective of this study was to evaluate recombinant antigens for their efficacy in a vaccine against $S$. stercoralis larvae. Three antigens, Ss-TMY-1, Ss-EAT-6, Ss-LEC-5 were selected because of their recognition by IgG from humans which was effective at killing the worms in collaboration with cells. In addition, Ss-eat-6 induced a significant reduction in larval survival after DNA immunization [23]. Two antigens, Ss-NIE-1 and Ss-IR, were selected based on their high degree of immunogenicity in humans infected with $S$. stercoralis [27, 29-31]. Results from the current study demonstrate that immunization with the single antigen Ss-IR induced high and consistent levels of protective immunity.

It was surprising that the antigen Ss-IR was protective whereas other immunogenic antigens or those identified by protective antibodies from humans were not protective. After immunization all of the antigens induced significant $\mathrm{IgG}$ responses, and even though SsTMY-1 induced the greatest levels of antigen specific IgG it was not protective. It is possible that antigens failed to induce protective immunity either because the target in the worm was inaccessible to the immune system or because these antigens required a different 
adjuvant to be effective, as has been seen in vaccine studies with the related parasite Strongyloides venezuelensis [32].

Based on analyses using confocal microscopy, it was determined that $\operatorname{IgG}$ from mice immunized with Ss-IR bound to the surface of the parasites. Proteomic analysis of $S$. stercoralis larvae identified the Ss-IR antigen after a short incubation in trypsin, suggesting that the antigen was on the larval surface [33]. However, using electron microscopy it was determined that IgG from mice immunized with Ss-IR bound to granules in the glandular esophagus. The reason why the two methods used to localize the antigens identified different locations may be due to the differences in fixation processes that cause changes in the retention of antigenicity or it may be that antibody could not penetrate into worms prepared for confocal microscopy. Protective IgM from mice immunized with live larvae bound to the surface of the cuticle, basal cuticle-hypodermis, coelomic cavity and glandular esophagus whereas protective IgG bound only to the basal cuticle-hypodermis and the coelomic cavity [21]. Antigens recognized by IgG from mice immunized with deoxycholate soluble proteins were found on the muscles and nerve cords [22]. Finally, antigens recognized by the protective human IgG were found predominantly on the surface and internal components of the cuticle and on the glands surrounding the esophagus [20]. The location of Ss-IR is therefore most similar to the site of the antigens recognized by the protective human $\mathrm{IgG}$.

Although it appears that protective immunity induced by immunization of mice with Ss-IR in alum is antibody dependent, the exact mechanism has not been defined. Antibodies from mice and humans require neutrophils [20-21, 34] and complement [19-20,35] to kill the worms. Furthermore, IgG from mice immunized with live larvae killed the challenge infection through a antibody dependent cellular cytotoxicity (ADCC) dependent mechanism, whereas IgM from mice immunized with live larvae, $\operatorname{IgG}$ from mice immunized with soluble antigens and human IgG all killed the worms through ADCC independent mechanisms [20-21]. The localization of Ss-IR on the surface of the worm would be conducive for an ADCC based mechanism whereas the internal location of the antigen would be supportive of an ADCC independent mechanism. It is indeed possible that both mechanisms may be functioning and this might explain the potency of the antigen in a vaccine.

In conclusion, Ss-IR has been identified as a highly effective antigen for use in a vaccine against $S$. stercoralis. The mechanism of action appears to be antibody dependent and the observation that it functions so successfully with alum as its adjuvant suggests that a Th2 response may be required. In addition, the fact that alum is widely used as an adjuvant in humans adds to the potential for this vaccine to be used as a prophylactic vaccine in humans protecting them from infection with $S$. stercoralis.

\section{Acknowledgments}

We thank Sandra Bonne-Année, Laura Kerepesi and Eric Wong for their expert and enthusiastic technical support. Special thanks to Yelena Oskov for assistance with the electron microscopy. This work was supported in part by NIH grants 1R56 AI076345 (to DA), RO1 AI 22662 (to JBL), RO1 AI 50668 (to JBL), RO1 AI082548 (to JBL), and P40 RR02512 (to JBL) and the Division of Intramural Research, NAID (to TBN).

\section{References}

1. Croker C, Reporter R, Redelings M, Mascola L. Strongyloidiasis-related deaths in the United States, 1991-2006. Am J Trop Med Hyg. 2010; 83:422-6. [PubMed: 20682893]

2. Keiser PB, Nutman TB. Strongyloides stercoralis in the Immunocompromised Population. Clin Microbiol Rev. 2004; 17:208-17. [PubMed: 14726461] 
3. Ramanathan R, Nutman T. Strongyloides stercoralis infection in the immunocompromised host. Curr Infect Dis Rep. 2008; 10:105-10. [PubMed: 18462583]

4. Montes M, Sanchez C, Verdonck K, Lake JE, Gonzalez E, Lopez G, Terashima A, Nolan T, Lewis DE, Gotuzzo E, White AC Jr. Regulatory T cell expansion in HTLV-1 and strongyloidiasis coinfection is associated with reduced IL-5 responses to Strongyloides stercoralis antigen. PLoS Negl Trop Dis. 2009; 3:e456. [PubMed: 19513105]

5. Horton J. Albendazole: a review of anthelmintic efficacy and safety in humans. Parasitology. 2000; 121 (Suppl):S113-32. [PubMed: 11386684]

6. Ikeda T. Pharmacological effects of ivermectin, an antiparasitic agent for intestinal strongyloidiasis: its mode of action and clinical efficacy. Nippon Yakurigaku Zasshi. 2003; 122:527-38. [PubMed: 14639007]

7. Geary TG, Woo K, McCarthy JS, Mackenzie CD, Horton J, Prichard RK, de Silva NR, Olliaro PL, Lazdins-Helds JK, Engels DA, Bundy DA. Unresolved issues in anthelmintic pharmacology for helminthiases of humans. Int J Parasitol. 2010; 40:1-13. [PubMed: 19932111]

8. Osei-Atweneboana MY, Awadzi K, Attah SK, Boakye DA, Gyapong JO, Prichard RK. Phenotypic evidence of emerging ivermectin resistance in Onchocerca volvulus. PLoS Negl Trop Dis. 2011; 5:e998. [PubMed: 21468315]

9. Bergquist R, Lustigman S. Control of important helminthic infections vaccine development as part of the solution. Adv Parasitol. 2010; 73:297-326. [PubMed: 20627146]

10. Samykutty A, Dakshinamoorthy G, Kalyanasundaram R. Multivalent vaccine for lymphatic filariasis. Procedia in Vaccinology. 2010; 3:12-8. [PubMed: 21709765]

11. Bethony J, Loukas A, Smout M, Brooker S, Mendez S, Plieskatt J, Goud G, Bottazzi ME, Zhan B, Wang Y, Williamson A, Lustigman S, Correa-Oliveira R, Xiao S, Hotez PJ. Antibodies against a secreted protein from hookworm larvae reduce the intensity of hookworm infection in humans and vaccinated laboratory animals. FASEB J. 2005; 19:1743-5. [PubMed: 16037096]

12. Bethony JM, Simon G, Diemert DJ, Parenti D, Desrosiers A, Schuck S, Fujiwara R, Santiago H, Hotez PJ. Randomized, placebo-controlled, double-blind trial of the Na-ASP-2 hookworm vaccine in unexposed adults. Vaccine. 2008; 26:2408-17. [PubMed: 18396361]

13. Ghosh K, Hawdon J, Hotez P. Vaccination with alum-precipitated recombinant Ancylostomasecreted protein 1 protects mice against challenge infections with infective hookworm (Ancylostoma caninum) larvae. J Infect Dis. 1996; 174:1380-3. [PubMed: 8940240]

14. Goud GN, Zhan B, Ghosh K, Loukas A, Hawdon J, Dobardzic A, Deumic V, Liu S, Dobardzic R, Zook BC, Jin Q, Liu Y, Hoffman L, Chung-Debose S, Patel R, Mendez S, Hotez PJ. Cloning, yeast expression, isolation, and vaccine testing of recombinant Ancylostoma-secreted protein (ASP)-1 and ASP-2 from Ancylostoma ceylanicum. J Infect Dis. 2004; 189:919-29. [PubMed: 14976610]

15. Mendez S, Zhan B, Goud G, Ghosh K, Dobardzic A, Wu W, Liu S, Deumic V, Dobardzic R, Liu Y, Bethony J, Hotez PJ. Effect of combining the larval antigens Ancylostoma secreted protein 2 (ASP-2) and metalloprotease 1 (MTP-1) in protecting hamsters against hookworm infection and disease caused by Ancylostoma ceylanicum. Vaccine. 2005; 23:3123-30. [PubMed: 15837211]

16. Zhan B, Perally S, Brophy PM, Xue J, Goud G, Liu S, Deumic V, de Oliveira LM, Bethony J, Bottazzi ME, Jiang D, Gillespie P, Xiao SH, Gupta R, Loukas A, Ranjit N, Lustigman S, Oksov Y, Hotez P. Molecular cloning, biochemical characterization, and partial protective immunity of the heme-binding glutathione S-transferases from the human hookworm Necator americanus. Infect Immun. 2010; 78:1552-63. [PubMed: 20145100]

17. Iriemenam NC, Sanyaolu AO, Oyibo WA, Fagbenro-Beyioku AF. Strongyloides stercoralis and the immune response. Parasitol Int. 2010; 59:9-14. [PubMed: 19892034]

18. Abraham D, Rotman HL, Haberstroh HF, Yutanawiboonchai W, Brigandi RA, Leon O, Nolan TJ, Schad GA. Strongyloides stercoralis: protective immunity to third-stage larvae inBALB/cByJ mice. Exp Parasitol. 1995; 80:297-307. [PubMed: 7895840]

19. Brigandi RA, Rotman HL, Yutanawiboonchai W, Leon O, Nolan TJ, Schad GA, Abraham D. Strongyloides stercoralis: role of antibody and complement in immunity to the third stage of larvae in BALB/cByJ mice. Exp Parasitol. 1996; 82:279-89. [PubMed: 8631379] 
20. Kerepesi LA, Nolan TJ, Schad GA, Lustigman S, Herbert DR, Keiser PB, Nutman TB, Krolewiecki AJ, Abraham D. Human immunoglobulin G mediates protective immunity and identifies protective antigens against larval Strongyloides stercoralis in mice. J Infect Dis. 2004; 189:1282-90. [PubMed: 15031798]

21. Ligas JA, Kerepesi LA, Galioto AM, Lustigman S, Nolan TJ, Schad GA, Abraham D. Specificity and mechanism of immunoglobulin M (IgM)- and IgG-dependent protective immunity to larval Strongyloides stercoralis in mice. Infect Immun. 2003; 71:6835-43. [PubMed: 14638770]

22. Herbert DR, Nolan TJ, Schad GA, Lustigman S, Abraham D. Immunoaffinity-isolated antigens induce protective immunity against larval Strongyloides stercoralis in mice. Exp Parasitol. 2002; 100:112-20. [PubMed: 12054701]

23. Kerepesi LA, Keiser PB, Nolan TJ, Schad GA, Abraham D, Nutman TB. DNA immunization with $\mathrm{Na}+\mathrm{K}+$ ATPase (Sseat-6) induces protective immunity to larval Strongyloides stercoralis in mice. Infect Immun. 2005; 73:2298-305. [PubMed: 15784574]

24. Lambrecht BN, Kool M, Willart MA, Hammad H. Mechanism of action of clinically approved adjuvants. Curr Opin Immunol. 2009; 21:23-9. [PubMed: 19246182]

25. Lindblad EB. Aluminium compounds for use in vaccines. Immunol Cell Biol. 2004; 82:497-505. [PubMed: 15479435]

26. Rotman HL, Schnyder-Candrian S, Scott P, Nolan TJ, Schad GA, Abraham D. IL-12 eliminates the Th-2 dependent protective immune response of mice to larval Strongyloides stercoralis. Parasite Immunol. 1997; 19:29-39. [PubMed: 9121838]

27. Ramanathan R, Burbelo PD, Groot S, Iadarola MJ, Neva FA, Nutman TB. A luciferase immunoprecipitation systems assay enhances the sensitivity and specificity of diagnosis of Strongyloides stercoralis infection. J Infect Dis. 2008; 198:444-51. [PubMed: 18558872]

28. Irvine M, Huima T, Prince AM, Lustigman S. Identification and characterization of an Onchocerca volvulus cDNA clone encoding a highly immunogenic calponin-like protein. Mol Biochem Parasitol. 1994; 65:135-46. [PubMed: 7935620]

29. Moore TA, Ramachandran S, Gam AA, Neva FA, Lu W, Saunders L, Williams SA, Nutman TB. Identification of novel sequences and codon usage in Strongyloides stercoralis. Mol Biochem Parasitol. 1996; 79:243-8. [PubMed: 8855562]

30. Ravi V, King TP, Andersen JF, Nutman TB, Neva FA. Strongyloides stercoralis recombinant NIE antigen shares epitope with recombinant Ves v 5 and Pol a 5 allergens of insects. Am J Trop Med Hyg. 2005; 72:549-53. [PubMed: 15891128]

31. Krolewiecki AJ, Ramanathan R, Fink V, McAuliffe I, Cajal SP, Won K, Juarez M, Di Paolo A, Tapia L, Acosta N, Lee R, Lammie P, Abraham D, Nutman TB. Improved diagnosis of Strongyloides stercoralis using recombinant antigen-based serologies in a community-wide study in northern Argentina. Clin Vaccine Immunol. 2010; 17:1624-30. [PubMed: 20739501]

32. Vlaminck J, Lopez-Aban J, Ruano AL, del Olmo E, Muro A. Vaccination against Strongyloides venezuelensis with homologue antigens using new immunomodulators. J Parasitol. 2010; 96:6437. [PubMed: 20557210]

33. Marcilla A, Sotillo J, Perez-Garcia A, Igual-Adell R, Valero ML, Sanchez-Pino MM, Bernal D, Munoz-Antoli C, Trelis M, Toledo R, Esteban JG. Proteomic analysis of Strongyloides stercoralis L3 larvae. Parasitology. 2010; 137:1577-83. [PubMed: 20388238]

34. Galioto AM, Hess JA, Nolan TJ, Schad GA, Lee JJ, Abraham D. Role of eosinophils and neutrophils in innate and adaptive protective immunity to larval Strongyloides stercoralis in mice. Infect Immun. 2006; 74:5730-8. [PubMed: 16988250]

35. Kerepesi LA, Hess JA, Nolan TJ, Schad GA, Abraham D. Complement component C3 is required for protective innate and adaptive immunity to larval Strongyloides stercoralis in mice. J Immunol. 2006; 176:4315-22. [PubMed: 16547268] 


\section{Highlights}

- Mice immunized with Ss-IR antigen develop resistance to Strongyloides stercoralis

- Ss-IR antibodies were localized to the parasite surface and glandular esophagus

- Serum collected from immunized mice passively transferred immunity

- $\quad$ Ss-IR may be suitable as a vaccine against human strongyloidiasis 


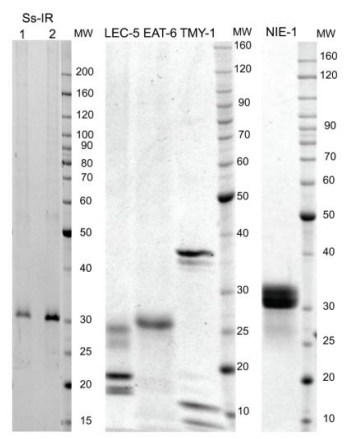

Figure 1.

Coomassie-stained SDS-PAGE of purified Ss-IR from two different runs as well as purified Ss-LEC-5, Ss-Eat-6, Ss-TMY-1 and Ss-NIE prepared for the vaccination studies. Molecular weight markers (MW) are recorded for individual analyses. 


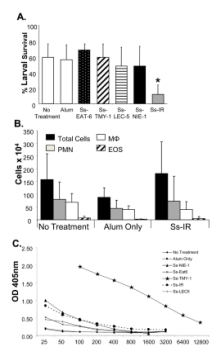

Figure 2.

Successful immunization of mice with Ss-IR in alum. Mice $(n=6)$ were immunized with recombinant antigens Ss-EAT-6, Ss-TMY-1, Ss-LEC-5, Ss-NIE-1 or Ss-IR in alum, with alum alone or left unvaccinated (No treatment). (A) Mean percent larval survival \pm standard deviations of the challenge larvae is presented. $(*)=$ statistically significant difference between larval recoveries from Ss-IR immunized mice and all other groups. (B) Means \pm standard deviations of the total cells, neutrophils (PMN), macrophages ( $\mathrm{M} \varphi)$ and eosinophils (EOS) infiltrating into the diffusion chamber. (C) IgG antibody titers against homologous antigens in mice immunized with the 5 recombinant antigens. 


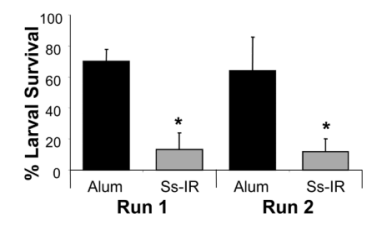

Figure 3.

Induction of protective immunity by different batches of baculovirus produced Ss-IR. Mice $(n=6)$ were immunized with 2 independent productions of recombinant antigens Ss-IR in alum or with alum alone. Mean percent larval survival \pm standard deviations of the challenge larvae is presented. $(*)=$ statistically significant difference between larval recoveries from Ss-IR immunized mice and mice vaccinated with alum alone. 

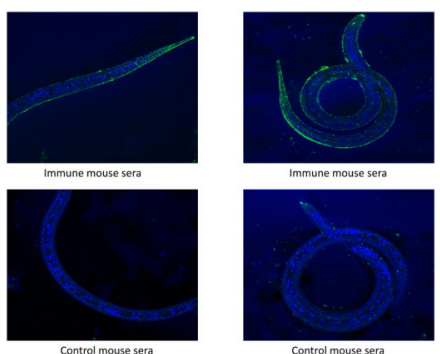

Figure 4.

Confocal microscopic localization of Ss-IR on S. stercoralis larvae using control mouse sera (alum only immunized; bottom panels) or immune mouse sera (Ss-IR immunized; Top panels). Ss-IR staining is shown in green; DAPI staining is shown in blue. 


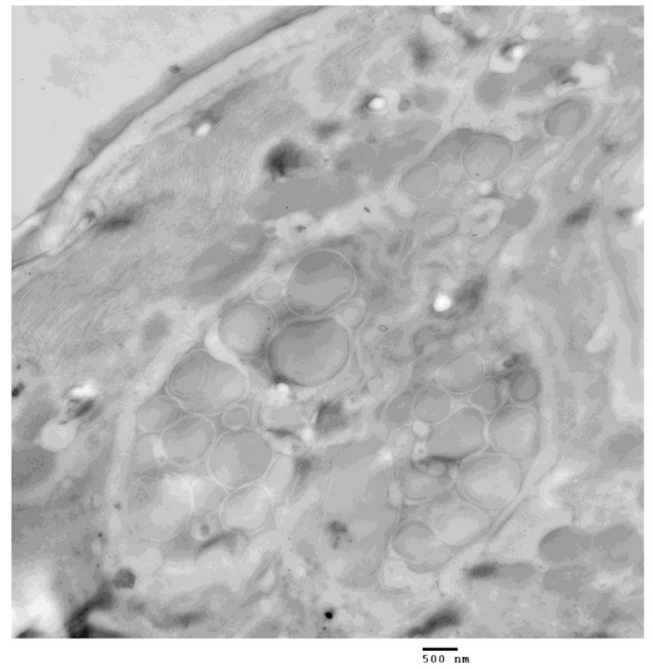

Control mouse sera

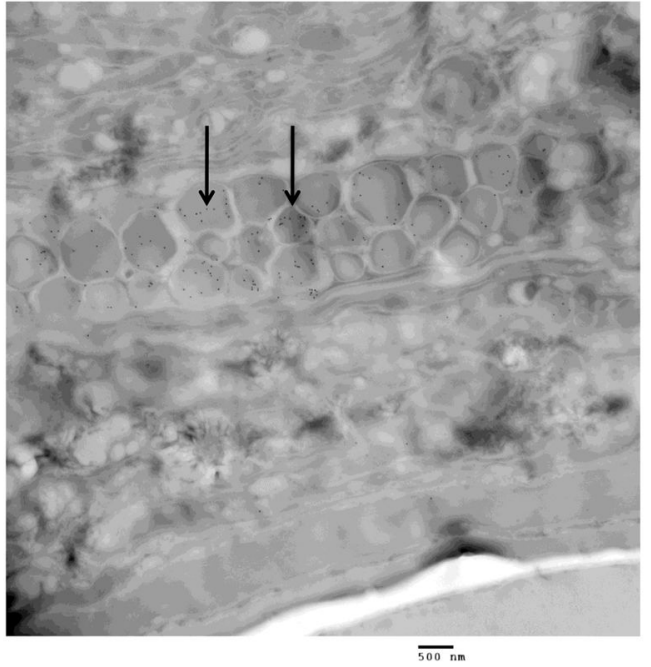

Immune mouse sera

Figure 5.

Immunoelectron microscopic localization of Ss-IR using control mouse sera (alum only; Panel A) or immune mouse sera (Ss-IR immunized; Panel B). Arrows point to the specific areas of staining. Magnification 11000x. 

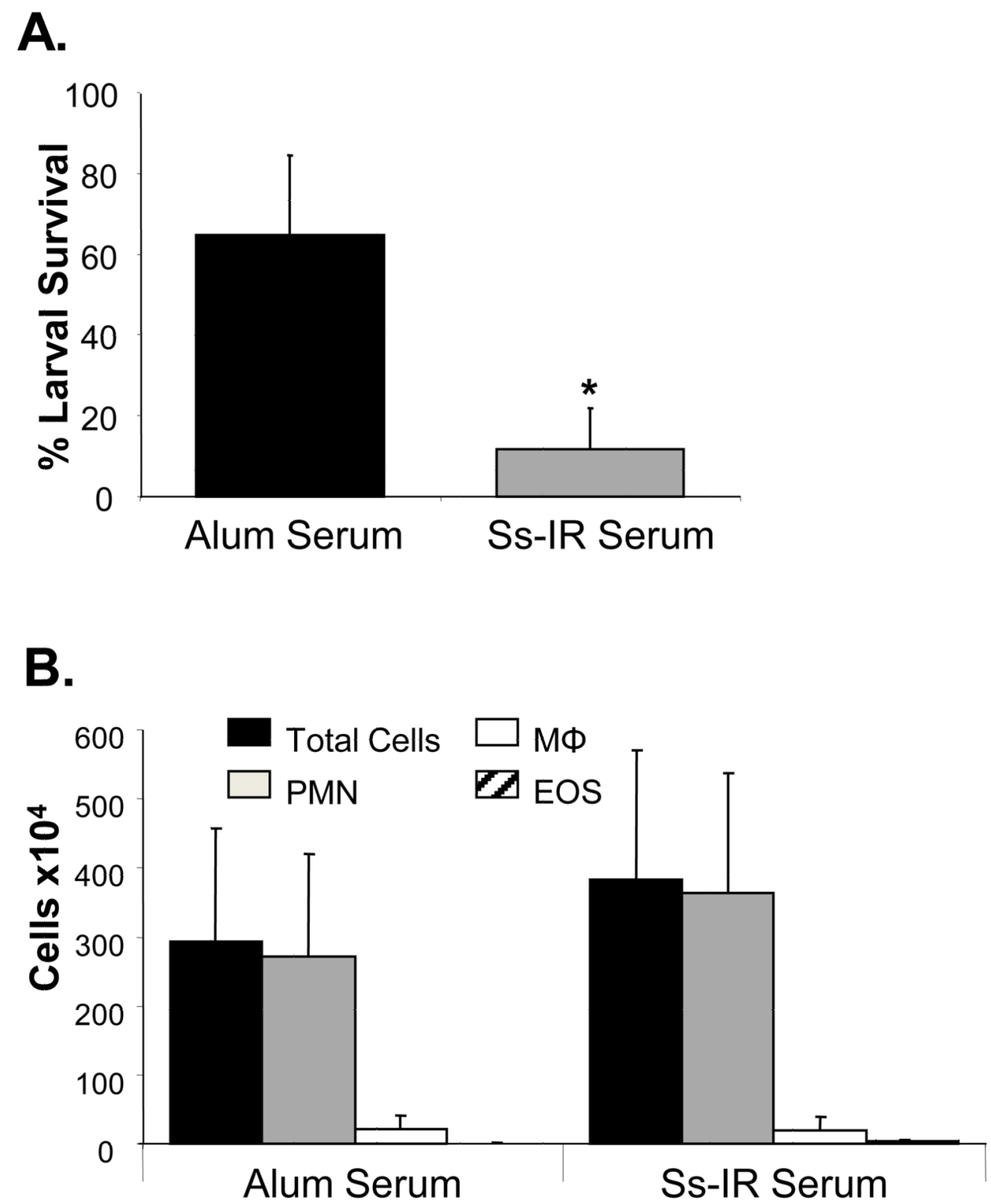

Figure 6.

Serum from Ss-IR immunized mice passively transfers immunity to challenge infection. Mice $(n=10)$ received passive transfer of serum derived from mice injected with alum (alum serum) or injected with alum and Ss-IR (Ss-IR serum). (A) Mean percent larval survival \pm standard deviations of the challenge larvae is presented. $(*)=$ statistically significant difference between larval recoveries from mice injected with serum from Ss-IR immunized mice as compared to mice injected with serum from mice injected with alum alone. (B) Means \pm standard deviations of the total cells, neutrophils (PMN), macrophages $(\mathrm{M} \varphi)$ and eosinophils (EOS) infiltrating into the diffusion chamber. 